\title{
THREE-DIMENSIONAL COMPUTED TOMOGRAPHIC ANGIOGRAPHY AS PREOPERATIVE EVALUATION OF A PATENT INTERNAL THORACIC ARTERY GRAFT
}

\author{
Atsushi Yamaguchi, MD, ${ }^{\text {a }}$ Hideo Adachi, MD, ${ }^{\text {a }}$ Takashi Ino, MD, ${ }^{\text {a }}$ and Yasuyuki Kobayashi, MD, ${ }^{\mathrm{b}}$ Saitama, Japan
}

Recent reports predict a further increase in the number of patients requiring reoperative coronary artery bypass grafting (CABG). ${ }^{1}$ Although reoperative $\mathrm{CABG}$ for patients with a patent left internal thoracic artery (LITA) graft is less common, injury of the patent LITA during sternotomy causes sudden and severe myocardial ischemia, sometimes leading to lethal myocardial infarction. Kaul and associates ${ }^{2}$ reported that $4(7.6 \%)$ of 52 patent LITAs were injured and required intravascular shunts to restore distal coronary circulation. Verkkala and colleagues ${ }^{3}$ also reported that $6(17.6 \%)$ of 34 patent LITAs were injured, and they concluded that a wellfunctioning LITA might be a relative contraindication for reoperative $\mathrm{CABG}$. Thus, most surgeons try to avoid any

From the Departments of Cardiovacular Surgery and Radiology, Omiya Medical Center, Jichi Medical School, Saitama, Japan.

Received for publication March 27, 2000; accepted for publication May 17, 2000.

Address for reprints: A. Yamaguchi, Department of Cardiovascular Surgery, Omiya Medical Center, Jichi Medical School, 1-847 Amanuma, Omiya, Saitama, Japan 330-8503.

J Thorac Cardiovasc Surg 2000;120;811-2

Copyright (C) 2000 by The American Association for Thoracic Surgery

$0022-5223 / 2000 \$ 12.00+0 \quad \mathbf{1 2 / 5 4 / 1 0 8 6 9 5}$

doi: $10.1067 / \mathrm{mtc} .2000 .108695$ damage to the patent LITA during sternotomy and dissection of cardiac adhesions. In the present case, 3-dimensional (3D) computed tomographic (CT) angiography was useful for recognizing the position of the patent LITA and avoiding vessel injury.

Clinical summary. A 75-year-old man had recurrent angina pectoris 8 years after primary CABG. Current coronary angiography revealed $90 \%$ stenosis of the left main coronary artery, the left circumflex artery, and the right coronary artery; an obstruction of the saphenous vein graft; and a patency of the LITA graft. Because the recurrent angina was refractory to medication and catheter interventions, reoperative $\mathrm{CABG}$ was proposed for the right coronary artery and the left circumflex artery by using a saphenous vein graft and a right internal thoracic artery graft.

The location of the patent LITA was preoperatively assessed to avoid injuring it during the operative procedure. Multislice helical CT scanning (Aquillion; Toshiba, Tokyo, Japan) was performed with a scanning time of $0.5 \mathrm{~s} / \mathrm{r}$ and a slice thickness/pitch of $1 \mathrm{~mm} / 6$. The 3D reconstruction method used was multiplanar reconstruction with a reconstruction pitch of $0.5 \mathrm{~mm}$. The $3 \mathrm{D}$ image demonstrates the distance between the LITA and the sternum, the midline, the aorta, and the pulmonary artery (Fig 1). On the basis of the 3D image, the sternum was dissected in the midline with an oscillator saw, the LITA was dissected from the sternum, and com- 

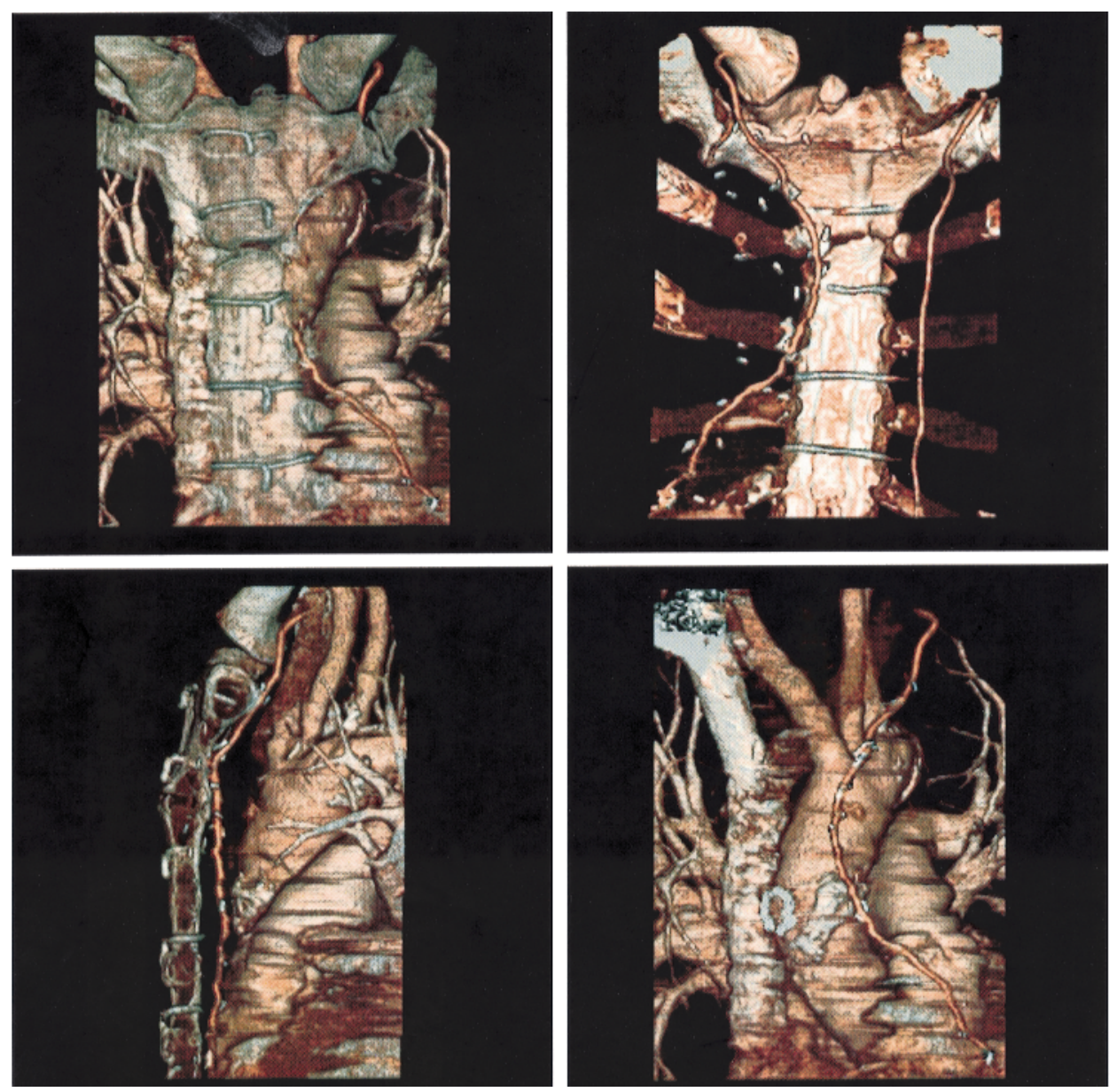

Fig 1. A patent LITA graft is detected in the frontal view (top left), posterior view (top right), and sagittal view (bottom left). The LITA adheres to the sternum at the level of the sternal angle and runs in front of the ascending aorta and the pulmonary artery (bottom right).

plete revascularization was safely achieved by means of cardioplegic arrest with a vascular clamp on the LITA.

Discussion. The 3D CT angiography is a combination of the helical CT scanning and computerized 3D reconstruction techniques. In these days, multislice helical CT scanning has demonstrated high-resolution 3D images through ultrahighspeed scanning, large-area imaging, and high-resolution volume data acquisition. ${ }^{4}$ The biggest advantage of this system is to provide helpful hints for surgeons by visualizing the ins and outs of complex cardiovascular structures in any region of interest. ${ }^{5}$ One disadvantage of the method is that it takes a couple of hours to manage plain 2D images and convert them into 3D images, although the progress of software and hardware will resolve this difficulty in the near future. We conclude that 3D CT angiography can be one of the most useful modalities in evaluation of the preoperative cardiovascular structures and can be beneficial for making a schema of safe operative maneuvers.

\section{REFERENCES}

1. Weintraub WS, Jones EL, Morris DC, King SB 3rd, Guyton RA, Craver JM. Outcome of reoperative coronary bypass surgery versus coronary angioplasty after previous bypass surgery. Circulation 1997;95:868-77.

2. Kaul TK, Fields BL, Wyatt DA, Jones CR, Kahn DR. Reoperative coronary artery surgery: early and late results and management in 1300 patients. J Cardiovasc Surg 1995;36:30312.

3. Verkkala K, Jarvinen A, Virtanen K, Keto P, Pillinen T, Salminen US, et al. Indications for and risks in reoperation for coronary artery disease. Scand J Thorac Cardiovasc Surg 1990;24:1-6.

4. Katada K. Current status and outlook for CT [in Japanese]. Shiniryo 1999;1:72-7.

5. Adachi H, Ino T, Mizuhara A, Yamaguchi A, Kobayashi Y, Nagai J. Assessment of aortic disease using three-dimensional CT angiography. J Card Surg 1994;9673-8. 